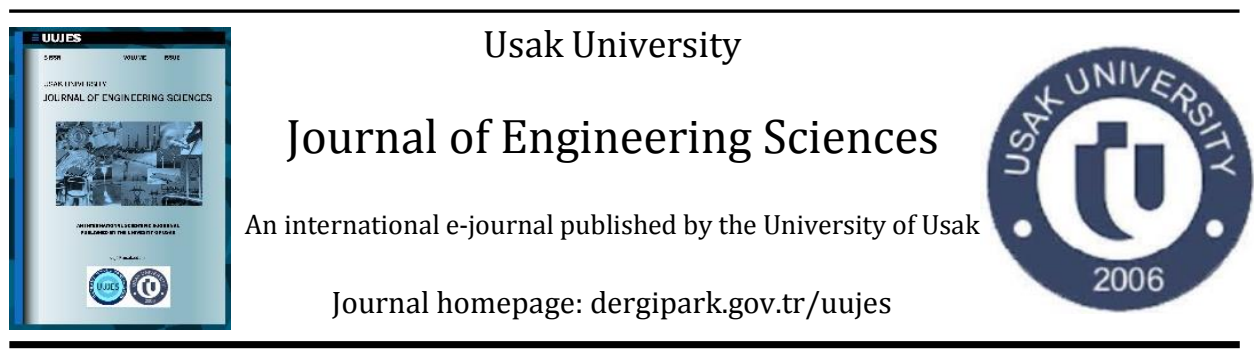

Research article

\title{
EFFECT OF FERMENTATION ON THE MILK ALLERGEN PROTEINS DURING YOGURT-MAKING
}

\author{
Özgür Tarhan ${ }^{1 *}$, Ahmet Kaya ${ }^{1,2}$ and Mustafa Gözler ${ }^{1}$ \\ ${ }^{1}$ Department of Food Engineering, Ușak University, Uşak, Türkiye \\ ${ }^{2}$ Muratbey Dairy Inc. Co., Uşak, Türkiye
}

Received: 05 December 2021 Revised: 11 December 2021 Accepted: 13 December 2021 Online available: 30 December 2021 Handling Editor: Jülide Öner

\begin{abstract}
Cow milk and dairy products have a great significance in human nutrition but may lead to concerns due to milk protein allergy. Reduction or elimination of cow milk allergy is mainly achieved by the destruction of allergenic epitopes in the molecular structure of relevant proteins via various treatments during dairy processing. Yogurt is one of the most consumed fermented dairy foods. The purpose of this study was to investigate the effect of fermentation on the protein content and molecular structure of milk during yogurt production. Protein profiles and structural features of the dairy samples collected at various steps of yogurt manufacturing were analyzed using electrophoresis and spectroscopy. Fermentation after pasteurization treatment remarkably altered the composition and structure of allergen proteins through unfolding, denaturation, and aggregation. This might suggest a correlation with the modified allergenicity of milk proteins in the end product.
\end{abstract}

Keywords: Yogurt, fermentation, milk allergens, protein, electrophoresis, FTIR.

(C)2021 Usak University all rights reserved.

\section{Introduction}

Despite its valuable nutrient content, especially for feeding neonates, cow milk is also associated with some immunological problems due to its proteins. Casein (CN), $~ 80 \%$, and whey proteins (WP), $\sim 20 \%$, are two major protein fractions in cow milk. CN fraction has $\alpha-, \beta-$, and $\kappa-\mathrm{CN}$ units with molecular weight in between 20-30 kDa. WP fraction has $\beta$ lactoglobulin, $\beta$-lg with $\sim 18.3 \mathrm{kDa}$; $\alpha$-lactalbumin, $\alpha$-la with $\sim 14.2 \mathrm{kDa}$; bovine serum albumin, BSA with $\sim 67 \mathrm{kDa}$; lactoferrin, LF with $\sim 80 \mathrm{kDa}$ and immunoglobulins, Igs with $\sim 15-150 \mathrm{kDa}$ [1]. CNs, $\beta$-lg, and $\alpha$-la are recognized as the major allergen fractions

\footnotetext{
*Corresponding author: Özgür Tarhan

E-mail: ozgur.tarhan@usak.edu.tr (ORCID: 0000-0001-7084-6253)

DOI: $10.47137 /$ uujes.1032643
}

(C)2021 Usak University all rights reserved. 
potentially leading to severe immunological reactions, whereas BSA, LF and Igs are known as the minor allergen fractions possibly causing low immunogenic response [2]. Cow milk allergy occurs due to the interaction between allergen milk proteins and the immune system, resulting in immediate IgE-mediated reactions [3]. Allergenicity is caused by IgEbinding allergen epitopes while antigenicity is caused by IgG-binding antigen epitopes of a suspected molecule [4]. Epitopes, the antigenic determinants in the protein structure are responsible for the allergenic and/or antigenic characteristics of the protein [5]. Two types of epitopes differing in structure can be sorted as follows: linear epitopes based on continuous amino acid sequence associated with the primary structure of the proteins, and conformational epitopes based on discontinuous amino acid sequence associated with the secondary and tertiary structure of the proteins [6, 7]. Both linear and conformational epitopes existing in different locations within the molecular structure of CN and WP fractions in milk have been reported in previous studies [8, 9]. According to those, modifications in the molecular structure of these epitopes through dairy processing can alter the reactive properties of milk proteins.

Yogurt is one of the most preferred fermented dairy products. In industrial production, after pasteurization $\left(\sim 85-90^{\circ} \mathrm{C}\right)$ and homogenization steps starter cultures were added to milk and incubated at $37-42{ }^{\circ} \mathrm{C}$ for $4-6$ hours on average. Once $\mathrm{pH}$ is reached about 4.5 , it is cooled down to stop the bacterial activity and further acid production. In case of homemade yogurts, milk is boiled for a while for pasteurization and concentration purposes, then one or two spoons of previous homemade yogurt are added and mixed in it. Finally, it is left for fermentation by covering with cloths to keep warm for about 6 hours, and refrigerated. All these treatments can alter the content and molecular conformation of milk proteins, which possibly modify the biological activity/reactivity of relevant proteins. The study presented changes in the content and structure of allergen milk proteins during yogurt-making through electrophoresis and spectroscopy.

During yogurt-making, the milk is processed through homogenization, pasteurization, evaporation/concentration, and fermentation. These processes can cause conformational changes in the protein structure through unfolding, denaturation and aggregation resulting in changed IgE-binding capacity of the relevant epitopes. These modifications can potentially enhance or diminish the allergenicity of milk proteins $[10,11]$. For instance, thermal processing significantly induces structural destabilization and denaturation of WPs since they are thermolabile [12]. Immunological assays indicated that heating at a certain temperature and time resulted in the partial destruction of epitopes in WPs, thus decreasing the binding affinity of the remaining allergenic epitopes $[13,14]$. However, CNs are considered heat stable due to their structure containing mostly linear epitopes associated with the primary structure. Thus, heat treatment can lead to only partial reduction or no change in their allergenicity $[15,16]$. Fermentation and enzymatic hydrolysis of milk can also lead to a decrease in allergenicity and/ or antigenicity due to the enhanced cleavage of relevant epitopes within protein structure $[17,18]$. Moreover, a synergistic effect on the reduction of immunoreactivity was observed during gastrointestinal digestion of fermented dairy products $[19,20]$. Currently, extensively hydrolyzed milk protein formulations are available and served as hypoallergenic products [17]. Here, we aimed to follow the differences in protein content and structure among industrial (national and local brands) and homemade yogurts for pre-understanding possible alterations in allergenicity/reactivity potential of milk proteins. This study is one of the first studies presented in this field.

Sodium dodecyl sulfate-polyacrylamide gel electrophoresis (SDS-PAGE) and capillary electrophoresis (CE) are commonly used techniques for the fractionation of proteins [20, 
21]. Electrophoretic mobility of proteins is achieved through their molecular weights and charges. Allergen proteins with $\mathrm{CN}$ and WP fractions in dairy products are resolved through SDS-PAGE and CE procedures previously [20-22]. Infrared spectroscopy (IR) is widely used to investigate the tertiary and secondary structure of proteins [23]. It facilitates the determination of conformational changes in protein structure occurring through various treatments during processing. Fourier Transform IR (FTIR) can provide valuable information about structural alterations regarding the unfolding, degradation and aggregation of milk proteins potentially resulted in modulation of antigen-binding epitopes on relevant peptides, subsequently diminished or elevated allergenicity [24, 25].

The purpose of this study was to investigate the changes in content and molecular structure allergen milk protein fractions in industrial and homemade yogurts using electrophoresis and spectroscopy. Qualitative analyses of CN and WP fractions in yogurt samples were considered to provide a preliminary understanding of the modified protein reactivity/ allergenicity relevant to the detected changes through fermentation.

\section{Materials and Method}

\subsection{Materials}

Yogurt samples, 2 national (N1, N2) and 1 local (L) brand were supplied from local markets in Uşak (Turkey). A traditional homemade yogurt $(\mathrm{H})$ sample was also used for comparison. All were stored in $+4{ }^{\circ} \mathrm{C}$ for the analyses. Electrophoresis chemicals and the standard marker were purchased from Bio-Rad Laboratories Inc (Hercules, CA, USA). Capillary column and the related chemicals were supplied by Agilent Technologies Inc. (CA, USA). All other chemicals were purchased from Sigma Aldrich Co. (St. Louis, MO, USA).

\subsection{Methods}

Yogurt samples were subjected to SDS-PAGE, capillary electrophoresis, and FT-IR analyses to follow compositional and structural changes in the allergen protein fractions ( $\mathrm{CN}$ and WP) during fermentation of milk.

\subsubsection{Sample Preparation}

Sample preparation part was adapted from Tarhan and Kaya (2021). To separate serum from the curd, $1 \mathrm{~g}$ of yogurt sample dissolved in $5 \mathrm{ml}$ ultrapure water was subjected to centrifugation at $4000 \mathrm{rpm}$ for $20 \mathrm{~min}$ and kept at $+4{ }^{\circ} \mathrm{C}$ for $30 \mathrm{~min}$. After the separation of the fat layer at the top, supernatant and pellet samples were used for the proposed analyses. One $\mathrm{ml}$ of supernatant was taken and diluted tenfold, and the pellet was dissolved in ultrapure water $(100 \mathrm{mg} / \mathrm{ml})$ for use in further analyses. Each analysis was repeated at least twice and a qualitative assessment was performed.

\subsubsection{Electrophoresis}

SDS-PAGE analysis was performed according to the Laemmli protocol [26]. Both pellet and serum samples were mixed with sample buffer (1:1) and boiled for 5 minutes to denature proteins. Twenty microliters of each sample were loaded to each well of gel and electrophoresis was carried out on 4 and $12 \%$ polyacrylamide gels at $60 \mathrm{~V}$ in the first 15 $\mathrm{min}$, then at $90 \mathrm{~V}$ for the following $90 \mathrm{~min}$ (MiniProtean, Bio-Rad Laboratories Inc., CA, USA). After staining with Coomassie Brillant Blue R250 and subsequent destaining steps, protein bands were examined. 
CE analysis was performed according to Tarhan and Kaya (2021) [22], using Agilent 7100 CE with diode array detection and Chemstation for Instrumental control (Agilent, CA, USA). Electropherograms of the pellet and serum samples were assessed qualitatively.

\subsubsection{FTIR Spectroscopy}

FT-IR measurements were carried out using a Perkin-Elmer 100 FT-IR spectrometer (Wesseley, MA, USA) equipped with a horizontal ATR sampling accessory, at room temperature. Samples $(\sim 100 \mu \mathrm{l})$ were placed onto the crystal surface and the measurements were taken in the range of 4000-400 cm-1. The resolution was $4 \mathrm{~cm}-1$ and 64 scans were recorded per spectrum with a scan speed of $1 \mathrm{~cm} / \mathrm{sec}$. A background was recorded before each measurement.

\section{Results and discussion}

\subsection{Protein Profiles in Yogurt Samples}

Protein fractions separated through SDS polyacrylamide gels were shown in Fig. 1. The CN fractions corresponding to the bands between $\sim 25-35 \mathrm{kDa}$ are comprised in pellets and major whey fractions, $\beta$-lg and $\alpha$-la with molecular weights of $\sim 18 \mathrm{kDa}$ and $\sim 14 \mathrm{kDa}$, respectively, are comprised in serum samples. As expected, CNs were exist in yogurt curd, however, some residual whey fractions including BSA ( $\sim 68 \mathrm{kDa}), \beta$-lg and $\alpha$-la were also found in pellet samples. Protein profiles were almost identical in yogurt samples of two national (N1 and N2) and one local (L) brands. Besides, a slight difference in band intensities and contents of pellet and serum protein fractions were observed in homemade (H) yogurt sample when compared to the national and local ones. This might have arisen from the activity of bacterial culture used for fermentation. Industrial yogurt production is made under definite conditions (temperature, time, dry matter content, etc.) using wellidentified starter cultures. However, in homemade yogurt production, culturing is made using previous homemade yogurts and the other conditions (eg. dry matter content) are not tightly controlled [28]. Thus, some differences can occur in the protein structure and content of these final fermented milk products. This may potentially affect the physicochemical properties and reactivity of allergen milk proteins as well.

Our SDS-PAGE findings were agreed with the current literature. Similar SDS-PAGE patterns of proteins in yogurt samples were indicated by Kumral (2015) [27]. Besides, Tolu and Altun (2021) compared some properties of industrial and homemade yogurts and reported that the protein content of both slightly differed due to the composition of milk processed to yogurt and other conditions such as dry matter content [28]. 


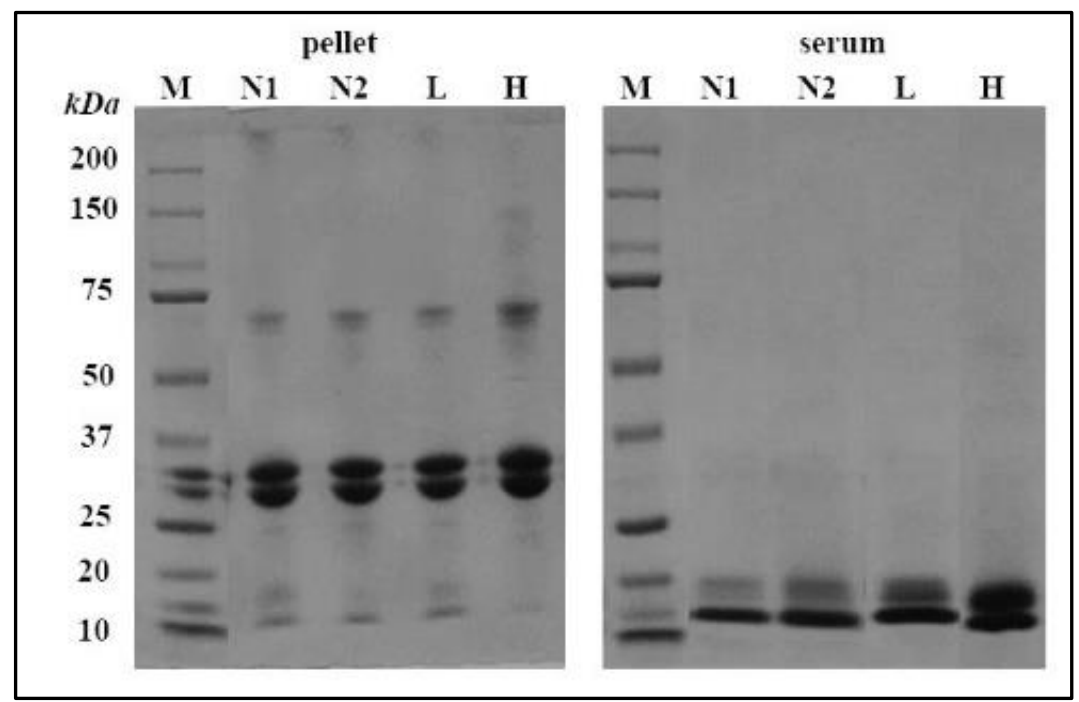

Fig. 1. SDS-PAGE profiles of yogurt samples (Lane M represents the standard marker). Pellets comprised CN fractions and serums comprised WP fractions: N1: national yogurt1, N2: national yogurt2, L: local yogurt, $\mathrm{H}$ : homemade yogurt

Capillary electrophoresis of the selected one yogurt sample of a national company (N1) and one homemade yogurt sample $(\mathrm{H})$ provided supportive information for SDS-PAGE analysis (Fig. 2). According to electropherograms of pellet and serum samples, CN and whey proteins were migrated separately. The migration times for $\mathrm{CN}$ fractions were about 10-20 min, whereas those for whey fractions were about 4-10 min. Electropherograms of standard CN and WPs, and raw/ pasteurized milk were given in our previous work [22]. Thus, the migration times of milk proteins given here were agreed with their corresponding standards reported previously.

Similar to SDS-PAGE findings, electropherogram of homemade yogurt pellet consisted of numerous peaks corresponding to a variety of protein fractions and digested peptides (Fig. 2). All these peptides may possess different biological activities attributed to the modified functionality of milk proteins in the end product. Protein digestion occurring during fermentation might lead to exposure and/or destruction of allergenic epitopes which might potentially affect the immunological reactivity of the final product. It has been reported that enzymatic action, proteolysis, and bacterial activity resulted in decreased milk protein allergenicity during digestion [29]. In another study, proteolytic degradation and immunoreactivity of $\beta$-lg isolated from fermented bovine milk were studied by SDSPAGE and CE [30]. They reported that the peptic digestion rate increased while immunological response decreased in both types of fermented milk due to proteolytic degradation of exposed allergenic sites in the relevant protein. There are many research works reporting the effect of processing on the reactivity of milk proteins [6, 31]. For instance, Umprierrezz et al (1999) and Alessandri et al (2018) have reported reduced allergenic responses to cow, goat and sheep cheeses containing heat treatment, rennet activity and fermentation periods $[29,32]$. They used immunological assays which are significantly needed for the exact determination of allergenicity. Here, we only propose to have some preliminary understanding of the allergenicity potential of milk proteins after fermentation by considering some constitutional and structural changes in them. 
Moreover, according to our knowledge there is lack of research investigating the reactivity and functionality of protein fractions in yogurt affected by fermentation process.

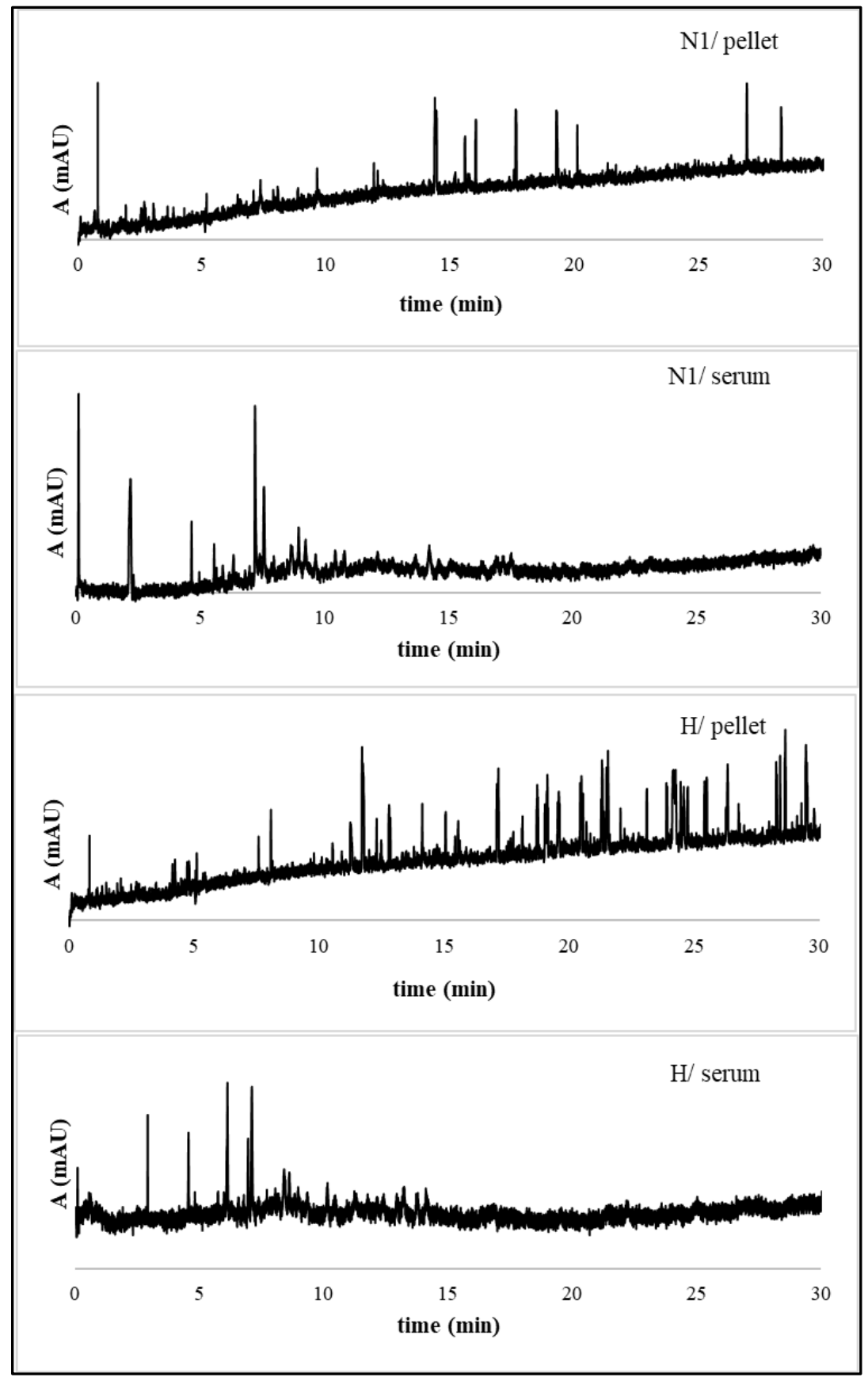

Fig. 2. Electropherograms of yogurt samples (From top to down $\mathrm{N} 1$ pellet and serum, $\mathrm{H}$ pellet and serum were given). Pellets comprised CN fractions and serums comprised WP fractions. N1: national yogurt1 and $\mathrm{H}$ : homemade yogurt 


\subsection{Structural Analysis of Proteins in Yogurt Samples}

FTIR spectra of pellet and serum samples of all yogurts tested were indicated in Fig. 3. Both groups exhibited different spectral features indicating different structural conformations of relevant proteins. Amide I and II stretching vibrations are mostly recognized with peaks at $\sim 1650$ to $1660 \mathrm{~cm}^{-1}$ and $\sim 1550$ to $1560 \mathrm{~cm}^{-1}$, respectively, corresponding to the $\alpha$-helix structure. The peaks at $\sim 1620$ to $1640 \mathrm{~cm}^{-1}$ and $\sim 1520-1540 \mathrm{~cm}^{-1}$ indicate $\beta$-sheet structures [31]. While Amide I vibrations were detected in pellets with higher absorbance than that in serum, Amide II vibrations were detected in serum with higher absorbance than that in the pellet. In general, similar spectral features were observed in all yogurt samples. This indicated that independent from industrial and homemade production style fermentation process revealed significant structural conformations in milk proteins. Besides, some signals in some samples had lower or higher intensity than the others, showing less or high exposure of corresponding structural features. Moreover, slight peak shifts, lost and newborn peaks indicated some insignificant differences in structural alterations of national, local and homemade yogurt samples.

FT-IR spectra of raw and pasteurized milk samples were presented in our previous work [22]. Based on those reported findings, significant conformational alterations in protein structure were detected in case of yogurt production. The most obvious one was the decrease in $\alpha$-helix content evident by lowered signals at $\sim 1650 / 1660$ and 1550/1560 $\mathrm{cm}^{-1}$. An increase in content of $\beta$-sheets and turns were attributed to the peaks at $\sim 1700$, 1640 , and $1540 \mathrm{~cm}^{-1}$. Especially, national brand yogurt samples revealed high intensity peaks at given wavenumbers. Allergen epitopes of milk proteins were reported to be found over $\beta$-sheet and turn structures [32]. Thus, increased $\beta$-sheet and turn structures may refer to the exposed allergen epitopes revealing enhanced reactivity of relevant milk proteins. However, immunoassay tests are needed to support this theory.

As previously stated, many IgE-binding epitopes were located on CN and WP fractions [33]. Combined treatments such as enzymatic hydrolysis subsequent to heating may reduce the antigenicity of milk proteins [16, 34]. Protein digestion reveals exposure of buried reactive/ functional peptides of the polypeptide chain. However, subsequent aggregation might lead to the burry of these peptides, giving rise to eliminated or hidden functionality or reactivity.

\section{Conclusion}

This study presented findings of electrophoresis and spectroscopy to analyze the effect of fermentation in the content and structure of protein fractions of milk. Exposure of milk proteins to various treatments during yogurt making may affect their immunogenicity mainly due to modification of the molecular structure of relevant proteins. CN and WP fractions known as the major milk allergens exposed to changes in content and molecular structure to some extend through fermentation. These changes can be attributed to the destruction of epitope structure, inactivated epitopes buried in molecular structure, new borne epitopes, and accessibility of inward epitopes. Various treatments during dairy processing significantly modify protein reactivity and functionality, which affect the physicochemical and nutritional quality of the final product. According to our knowledge, this is the first research work dealing with the effect of fermentation on allergen milk proteins in different yogurt samples by considering their reactivity. Immunological tests will provide more comprehensive data for the evaluation of allergy to yogurt in correlation with the changes occurring in the protein structure. 


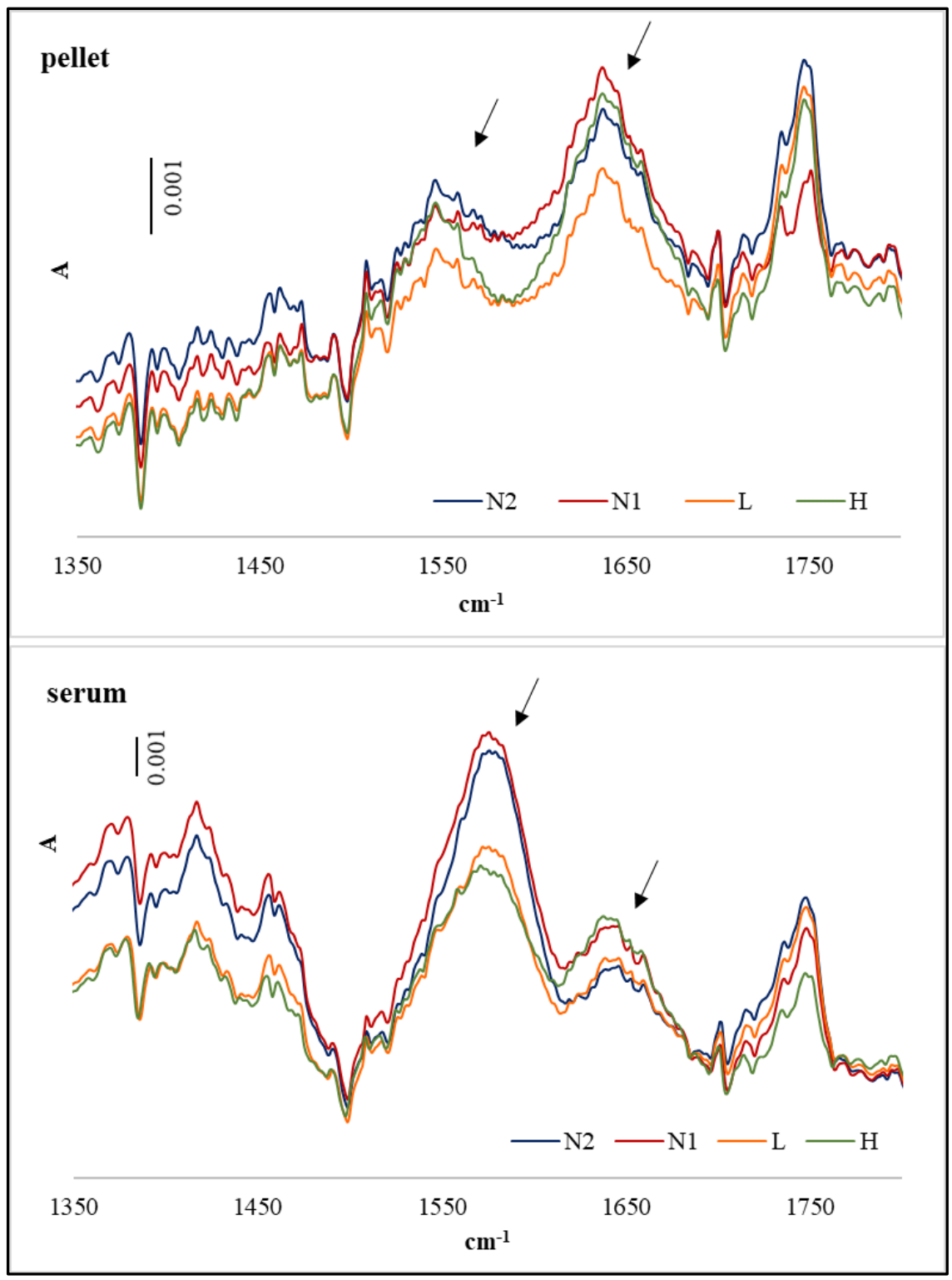

Fig. 3. FTIR spectra of yogurt samples. Pellet consisted CN fractions and serum contained WP fractions: N1: national yogurt1, N2: national yogurt2, L: local yogurt, H: homemade yogurt

\section{Acknowledgment}

This work has been financially supported by Ușak University Scientific Research Projects Department with the projects (UBAP06/TP044/2017). The authors would like to thank Dr. Senem Şanlı and Dr. Eyüp Yıldırır for their valuable helps in Capillary electrophoresis and FTIR studies, respectively. 


\section{References}

1. De Jong N, Visser S, Olieman C. Determination of milk proteins by capillary electrophoresis. Journal of Chromatography A. 1993;652(1):207-13.

2. Caira S, Pizzano R, Picariello G, Pinto G, Cuollo M, Chianese L, et al. Allergenicity of milk proteins. Milk protein. 2012;4.

3. El-Agamy E. The challenge of cow milk protein allergy. Small Ruminant Research. 2007;68(1-2):64-72.

4. Bogahawaththa D, Chandrapala J, Vasiljevic T. Modulation of milk immunogenicity by thermal processing. International dairy journal. 2017;69:23-32.

5. Wal J-M. Cow's milk proteins/allergens. Annals of Allergy, Asthma \& Immunology. 2002;89(6):3-10.

6. Kleber N, Krause I, Illgner S, Hinrichs J. The antigenic response of $\beta$-lactoglobulin is modulated by thermally induced aggregation. European Food Research and Technology. 2004;219(2):105-10.

7. Konstantinou GN, Kim JS. Paradigm shift in the management of milk and egg allergy: baked milk and egg diet. Immunology and Allergy Clinics. 2012;32(1):151-64.

8. Järvinen K-M, Chatchatee P, Bardina L, Beyer K, Sampson HA. IgE and IgG binding epitopes on $\alpha$-lactalbumin and $\beta$-lactoglobulin in cow's milk allergy. International archives of allergy and immunology. 2001;126(2):111-8.

9. Villa C, Costa J, Oliveira MBP, Mafra I. Bovine milk allergens: A comprehensive review. Comprehensive Reviews in Food Science and Food Safety. 2018;17(1):137-64.

10. Rahaman T, Vasiljevic T, Ramchandran L. Effect of processing on conformational changes of food proteins related to allergenicity. Trends in Food Science \& Technology. 2016;49:24-34.

11. Verhoeckx KC, Vissers YM, Baumert JL, Faludi R, Feys M, Flanagan S, et al. Food processing and allergenicity. Food and Chemical Toxicology. 2015;80:223-40.

12. Spotti MJ, Tarhan Ö, Schaffter S, Corvalan C, Campanella OH. Whey protein gelation induced by enzymatic hydrolysis and heat treatment: Comparison of creep and recovery behavior. Food Hydrocolloids. 2017;63:696-704.

13. Bu G, Luo Y, Zheng Z, Zheng H. Effect of heat treatment on the antigenicity of bovine $\alpha$-lactalbumin and $\beta$-lactoglobulin in whey protein isolate. Food and Agricultural Immunology. 2009;20(3):195-206.

14. Rahaman $\mathrm{T}$, Vasiljevic $\mathrm{T}$, Ramchandran L. Conformational changes of $\beta$ lactoglobulin induced by shear, heat, and $\mathrm{pH}-$ Effects on antigenicity. Journal of dairy science. 2015;98(7):4255-65.

15. Bhat MY, Dar TA, Singh LR. Casein proteins: structural and functional aspects. Milk proteins-from structure to biological properties and health aspects InTech, Rijeka. 2016:1-17.

16. Xu Q, Shi J, Yao M, Jiang M, Luo Y. Effects of heat treatment on the antigenicity of four milk proteins in milk protein concentrates. Food and agricultural immunology. 2016;27(3):401-13.

17. Niggemann B, Von Berg A, Bollrath C, Berdel D, Schauer U, Rieger C, et al. Safety and efficacy of a new extensively hydrolyzed formula for infants with cow's milk protein allergy. Pediatric allergy and immunology. 2008;19(4):348-54.

18. Yao M, Xu Q, Luo Y, Shi J, Li Z. Study on reducing antigenic response and IgEbinding inhibitions of four milk proteins of Lactobacillus casei 1134. Journal of the Science of Food and Agriculture. 2015;95(6):1303-12. 
19. Fotschki J, Szyc A, Wróblewska B. Immunoreactivity of lactic acid-treated mare's milk after simulated digestion. Journal of Dairy Research. 2015;82(1):78-85.

20. Wróblewska B, Kaliszewska A. Cow's milk proteins immunoreactivity and allergenicity in processed food. Czech Journal of Food Sciences. 2012;30(3):2119.

21. Omar A, Harbourne N, Oruna-Concha MJ. Quantification of major camel milk proteins by capillary electrophoresis. International Dairy Journal. 2016;58:315 .

22. Tarhan Ö, Kaya A. Investigation of the compositional and structural changes in the proteins of cow milk when processed to cheese. LWT. 2021;151:112102.

23. Barth A. Infrared spectroscopy of proteins. Biochimica et Biophysica Acta (BBA)-Bioenergetics. 2007;1767(9):1073-101.

24. Farrell Jr H, Wickham E, Unruh J, Qi P, Hoagland P. Secondary structural studies of bovine caseins: temperature dependence of $\beta$-casein structure as analyzed by circular dichroism and FTIR spectroscopy and correlation with micellization. Food Hydrocolloids. 2001;15(4-6):341-54.

25. Gomaa A, Boye J. Impact of irradiation and thermal processing on the immunochemical detection of milk and egg allergens in foods. Food research international. 2015;74:275-83.

26. Laemmli U. Glycine-SDS-PAGE for separation of proteins. Nature. 1970;227(5).

27. TOLU A, ALTUN I. Comparison of homemade and commercial yoghurt in Van province, Turkey. Food Science and Technology. 2021.

28. Kumral A. Nutritional, chemical and microbiological changes during fermentation of tarhana formulated with different flours. Chemistry Central Journal. 2015;9(1):1-8.

29. Alessandri C, Sforza S, Palazzo P, Lambertini F, Paolella S, Zennaro D, et al. Tolerability of a fully maturated cheese in cow's milk allergic children: biochemical, immunochemical, and clinical aspects. PloS one. 2012;7(7):e40945.

30. Maier I, Okun VM, Pittner F, Lindner W. Changes in peptic digestibility of bovine $\beta$-lactoglobulin as a result of food processing studied by capillary electrophoresis and immunochemical methods. Journal of Chromatography B. 2006;841(1-2):160-7.

31. Bu G, Luo Y, Chen F, Liu K, Zhu T. Milk processing as a tool to reduce cow's milk allergenicity: a mini-review. Dairy science \& technology. 2013;93(3):211-23.

32. Umpierrez A, Quirce S, Maranon F, Cuesta J, Garcia-Villamuza Y, Lahoz C, et al. Allergy to goat and sheep cheese with good tolerance to cow cheese. Clinical and experimental allergy: journal of the British Society for Allergy and Clinical Immunology. 1999;29(8):1064-8.

33. Tarhan Ö, Tarhan E, Harsa Ş. Investigation of the structure of alpha-lactalbumin protein nanotubes using optical spectroscopy. Journal of Dairy Research. 2014;81(1):98-106.

34. Niemi M, Jylhä S, Laukkanen M-L, Söderlund H, Mäkinen-Kiljunen S, Kallio JM, et al. Molecular interactions between a recombinant IgE antibody and the $\beta$ lactoglobulin allergen. Structure. 2007;15(11):1413-21.

35. Matsuo H, Yokooji T, Taogoshi T. Common food allergens and their IgE-binding epitopes. Allergology International. 2015;64(4):332-43.

36. Sletten GB, Holden L, Egaas E, Faeste CK. Differential influence of the degree of processing on immunogenicity following proteolysis of casein and $\beta$ lactoglobulin. Food and agricultural immunology. 2008;19(3):213-28. 